\title{
The Evaluation Of User Acceptance Of An Iban Digital Story Telling (IDST) Application Among Iban Language Teachers
}

\author{
Aslina Saad ${ }^{1}$, Kenneth Robin ${ }^{2}$, Saira Banu Omar Khan ${ }^{1}$ and Nor Hasbiah \\ Ubaidullah $^{1}$ \\ ${ }^{1}$ Computing Department, Computing \& Creative Industry, Tanjong Malim, UPSI, \\ 35900,Malaysia \\ ${ }^{2}$ Sek. Keb. Nanga Entabai, 96600 Julau,Sarawak
}

\begin{abstract}
The subject of Iban language for Year One's students is taught with elements of children's story. However, a preliminary investigation found that the current approach in teaching this subject using a textbook and audio narration is not efficacious. Thus, an Iban Digital Story Telling (IDST) application was developed to assist teachers in teaching Iban language. The aim of this study is to examine the acceptance of DST application in terms of ease of use and usefulness among teachers who teach Iban language in several primary schools. The study used a qualitative approach based on interviews involving 10 teachers, who were recruited from several primary schools in Sarawak, Malaysia. The analysis of qualitative data showed that all teachers rated the usefulness and ease of use of the IDST application to be high, which together helped them to teach the subject matter with more efficacy. Given these promising results, such a novel learning application can be used as an alternative teaching tool to further improve the current practice of teaching Iban language to primary school children.
\end{abstract}

\section{KEYWORDS}

Digital Story Telling, User Acceptance, Usefulness, Ease of Use, Iban Language Teachers

\section{INTRODUCTION}

As one of the efforts to preserve art and culture among the new generation, the curriculum of Iban language for Year One pupils has been reformed by introducing elements of children story in Unit 10 : Ensera Kitai (Folklores). In this unit, children story serves as the main medium for teaching and learning . According to Chemaline Osup in [1], Iban language has been taught for almost 47 years in Sarawak. Chronologically, this local language was first taught at the secondary level before being introduced to tertiary level. Later, Iban language was introduced in primary schools throughout Sarawak. Nonetheless, the lack of novel aids at such schools, among others, has impeded the process of teaching and learning of Iban language.

Against such backdrop, the researchers carried out a preliminary study based on a qualitative approach, namely interview and observation, involving 15 respondents who were learning the subject matter at four primary schools in Julau district. The findings showed that teachers relied on textbook as the main method in teaching Unit 10 of the Iban language. More revealingly, the findings found that new teachers were facing a number of problems due to their lack of experience and expertise in storytelling, resulting in students becoming less motivated and less focused. Furthermore, such conventional learning method was found to be burdensome to teachers when they had to repeat the same stories as requested by students. Arguably, repeating a story multiple times may not only be tiring but also be prone to making mistakes, as the tones and styles in the 
narration will vary considerably. In addition, some students complained that they had trouble in understanding such stories.

Additionally, existing audio learning aids, such as audio mp3 files, had not been effectively utilized, which occasionally had distracted students from learning. Arguably, such distractions were inevitable, as students might have to imagine the audio contents continually throughout the audio narration. Consequently, students would be cognitively overwhelmed to fully grasp the meaning of the story. Above all, the respondents unanimously agreed that learning arts in Iban language was extremely difficult. Hence, it becomes imperative for teachers of the subject matter to equip themselves with sufficient teaching skills to impart knowledge to students. The same findings also revealed that all the teachers surveyed agreed that more multimedia learning materials were needed to improve the teaching of Iban language. In particular, new teachers strongly opined that such learning materials could help lessen their teaching workload. The survey on existing educational products (in either digital format or print format) indicated that publication of Iban folklores was extremely limited. As such, it was hardly surprisingly that teachers had to continually use existing learning resources in the teaching and learning process.

Currently, the educational market is replete with digital children stories in many major languages, notably in English. Studies have shown that the use of digital children stories had positively affected students' learning performance and motivation. Nonetheless, several scholars have raised concerns about the quality of such materials. For example, Peng [2] argues that most children stories have been published merely for financial gains and entertainment, with scant regard for educational purposes. Invariably, these materials may be used in the teaching and learning process for the sake of fun and excitement. Of course, digital children stories can be developed with quality educational elements to teach students moral values, but such digital materials are very limited that hardly have an impact on student learning [2].

Hence, the lack of digital children stories in Iban language provided the impetus for the researchers to carry out this study. Specifically, the main aim of this study was on the development of digital story telling (IDST) application. Arguably, the successful adoption of any educational application is determined by the acceptance of users to ensure it will be used consistently and persistently. In this regard, it is important to understand why a particular technology will be accepted or rejected by users [3]. Hence, this study also focused on examining the acceptance and satisfaction of Iban language teachers in using such application in Malaysia. In particular, two factors that influence user acceptance, namely usefulness and ease of use, were evaluated. Three research objectives to guide the study were formulated as follows:

a. To develop a IDST application for teaching Iban language

b. To evaluate the usefulness of the IDST

c. To evaluate the ease of use of the IDST

To facilitate discussion, this paper is organized as follows: Section 2 discusses the review of literature related to digital storytelling, Section 3 elaborates the research methodology of the study, Section 4 discusses the data analysis and main discussion, and Section 5 concludes and summarizes the discussion of the study.

\section{LITERATURE REVIEW}

It has been widely acknowledged that the use of multimedia applications in the learning process helps expose children to exciting, engaging learning experiences, as multimedia elements can exploit various senses of humans, notably seeing and hearing senses through the eyes and ears, respectively. Thus, learning using multimedia is deemed more effective that learning using a single medium, as $80 \%$ of learning of humans depends on visual and aural perceptions [4]. Hence, such dependency on multi-sensorial learning may entail using multimedia elements to help enrich 
and enhance students' learning experiences. Arguably, DST applications with multimedia elements will be able to help improve learning through engaging storytelling. In fact, according to Pitler [5] as cited in [6], such technology integration in the classroom can create a conducive learning environment in which teachers and students will be able to engage in effective teaching and learning, respectively. In addition, such technology integration can not only improve students' learning, understanding, and achievement but also augments their motivation to learn, encourages collaborative learning, and develops critical thinking and problem-solving strategies [5]. Studies have shown digital children stories are able to motivate students and heighten their interest in learning.

Specifically, Pieterse and Quilling [7] state that previous research shows that digital story-telling can be a successful educational tool to deal with emotive issues. This is inline with Psomos and Kordaki [8], digital storytelling, the modern and challenging successor of storytelling, emerged over the last few years as a powerful teaching and learning tool, engaging both teachers and their students. In the 21 st century, we have started to tell stories using computer-based tools. As with traditional storytelling, digital storytelling focuses on a specific topic, has characters, a setting and a plot, and contains a particular point of view. But, by incorporating images, audio narration, video clips and/or music alongside traditional text, we obtain a more dynamic story, which captivates learners and enhances their creativity as well as their English language skill [9]. Bran [9] added that stories are the bedrock of every culture which allow people to understand someone else's experiences in a personal way, thus creating empathy. Digital stories build on traditional stories and provide affective learning that can lead the learner to a desire for more cognitive learning.

However, of late, teachers and instructors are slowly neglecting the use of such children stories as a medium for learning. Partly, the lack of use lies with the low educational values of digital children stories, as their developments are not based on sound learning principles but are focused more on commercial and entertainment values [2]. This misplaced focus is unfortunate, as research has shown that parents would like to use quality DST products that have both entertainment and motivational elements. Sadly, most DST products available in the market lack these motivational elements. In fact, Miswan, Hamedi, and Saad [10] found that a majority of the learning applications are not efficacious due to two main reasons. First, the contents of these applications are too focused on graphics, effectively neglecting the required educational components. Second, even though the learning applications may have sufficient educational contents, the delivery of such contents are too stereotyped and stale. As such, Tsai and Huang [11] assert that more interactive elements should be embedded in DST applications to make them both educational and entertaining. In this regard, more efforts are needed to not only develop such novel applications but also carry out research on their teaching efficacies [12].

The integration of technology in language learning has become a popular research focus nowadays. Arguably, most available DST applications are too rigid in their presentation, thus rendering them ineffective to attract students' attention in learning. Thus, more research is required to improve the design of such applications to make them become appealing and flexible in delivering learning contents ([13]; [14]). In this respect, Kukulska-Hulme and Shield [13] (cited in [10]) emphasize that the development of mobile learning applications for language should focus on contents and design. Furthermore, the development of learning materials and activities should focus on learning contents. Typically, such development tends to pay more weight to delivering contents by a formal approach rather than by a leisure approach. In contrast, the development of applications emphasizing on design aspects tends to use a natural, informal approach to deliver learning contents. Such differences in approach is hardly surprising, as the sophistication of tools and software has little impact on users' performance. In fact, the development of learning applications should take relevant pedagogical aspects into account based on learners' needs [15]. 
Clearly, students will be able to improve their interest and engagement in learning using novel learning applications. Nevertheless, almost all the applications need further improvement to be able to fully meet students' learning needs [16]. Of late, many studies have been devoted to validating the effectiveness of computer-based learning and mobile learning using various approaches [12]. As such, the effectiveness of learning based on storytelling should be examined in several contexts, in particular in learning Iban language. To facilitate such research, the development of DST for children needs to be further refined to emphasize aspects of learning and teaching. Hence, digital storytelling in Iban language needs to undergo a comprehensive transformation to ensure students will be exposed to not only the entertainment aspects but also educational aspects as well. To achieve such an educational exposure, the design of DST applications should focus on multimedia and pedagogical elements to help develop effective digital storytelling materials.

\section{METHODOLOGY}

The methodology of this research encompasses both the development and evaluation of the IDST application. The development of DST was based on ADDIE model, which consist of five phases, namely Analysis, Design, Development, Implementation, and Evaluation. A qualitative approach using interview was used in the evaluation of this application. Figure 1. illustrate methodology for this research together with main activities within each phase.

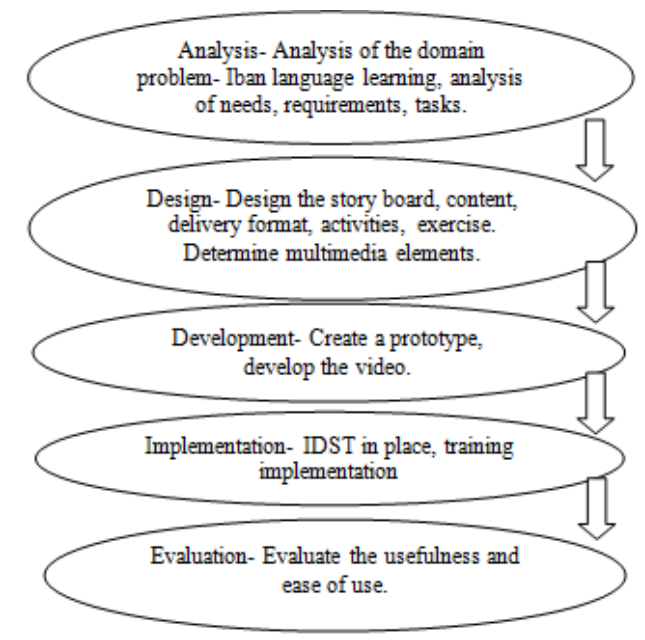

Figure 1: ADDIE Methodology for IDST research

In the analysis phase, a number of techniques were used, namely structured interview, literature review, and observation. Collectively, this approach helped the researchers to examine the current teaching and learning practice of Iban language in a practical context. Based on this analysis, the needs of users for IDST application could be defined clearly.

This study involved two types of design, namely the design of courseware and the design of video story. For the former, a story board was conceptualized to help guide the development of IDST. For the latter, a story board with scripts, characters, and background music were earmarked to create the video. In addition, multimedia elements, such as animation, texts, graphics, and video were determined accordingly. In addition, the appropriate interface design and the colours for characters were also identified. Likewise, the proper navigational links were also determined to ensure a smooth flow of activities of the courseware. Together, these selected design criteria were used to guide the development of the IDST (see the details in Section 4). The prototype of this 
application would then be used as a teaching and learning tool in the classroom prior to evaluating its efficacy. After two weeks of deployment, the efficacy of IDST was evaluated qualitatively (see the details in Section 5).

The research method used in the evaluation of user acceptance of the application was based on a qualitative approach through interview. This method helped the researchers to collect data pertaining to the user acceptance of IDST application, namely, usefulness (PU) and ease of use (PEOU). For the interview, 10 teachers were recruited from several schools in the state of Sarawak, particularly in the districts of Julau and Kapit, who were teaching the subject matter. Before the interview, they were given the learning application to be used in their classroom for two weeks. Then, interviews were held at their respective schools, with each interview session lasting between 30 minutes and 45 minutes. The instrument used for the structured interviews was developed based on the Technology Acceptance Model (TAM) to help collect information regarding the usefulness and ease of use of the digital learning application.

\section{THE DEVELOPMENT OF IDST}

Essentially, the IDST consists of three parts, namely the synopsis of the story, contents of the story, and reinforcement practice. In the development phase, multimedia elements, such as text, graphics, audio, animation, and video were included in the storytelling project according to the outlines of the story board, which was prepared at the design phase. Additionally, the development of the video involved the modelling of characters of the story. To complete this development, background music and audio were mixed and combined into the learning application. Carrying out the above activities entailed the use of a host of software packages as follows

\subsection{Development of Courseware}

Figure 2 shows the main page of the learning application showing the title and graphical characters of the story. Users need to unlock this page before logging in on the application. To unlock the application, users are required to select and drag the unlock key to a key hole. The purpose of the unlocking technique is to add an extra interactive element to the application such that users, namely children, will be exposure to new experience that is fun and interesting. The use of suitable colours depicting a lush field against the vast open skies and a child passionately reading a book invokes a feeling of happiness. In addition, the use of suitable background music makes users feel content and relaxed. Moreover, a button with audio guides users to navigate with ease. Figure 2 shows the main page of the IDST.

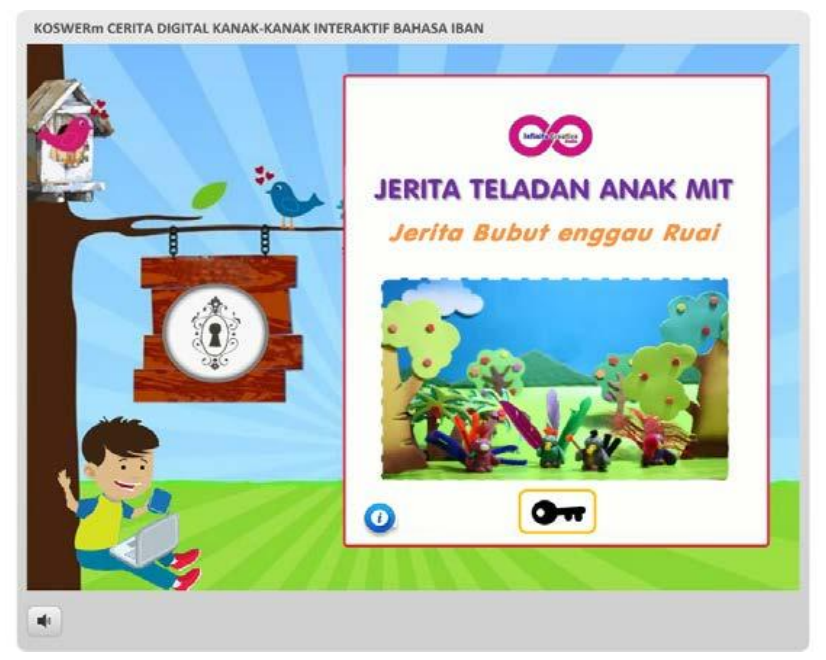

Figure 2: The main page of the IDST 
The International Journal of Multimedia \& Its Applications (IJMA) Vol.9, No.4/5/6, December 2017

The combination of attractive colours helps attract users' attention and make them enthusiastic when using the application. The interface was designed to be simple and organized, with selection menu located at its left side (see Figure 3). Furthermore, each menu has its own transition to further improve the application's ease of use. Intuitively, users will be able to use the application using such a user-friendly interface design. Figure 2 shows the menu interface of the IDST.

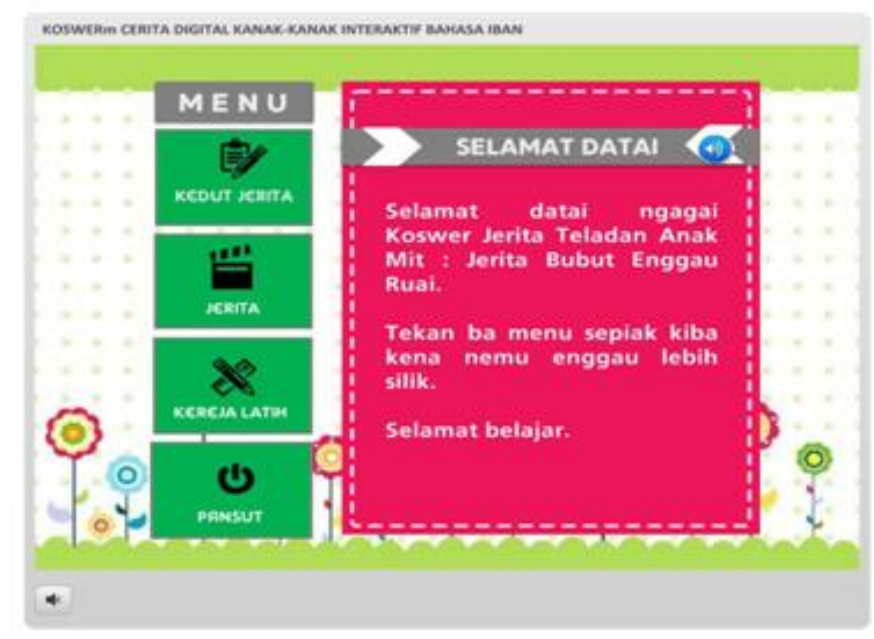

Figure 3: The menu interface of the IDST

Figure 4 shows the page highlighting the synopsis of the story, with an audio "teaser", when users press the "Kedut Jerita" button.

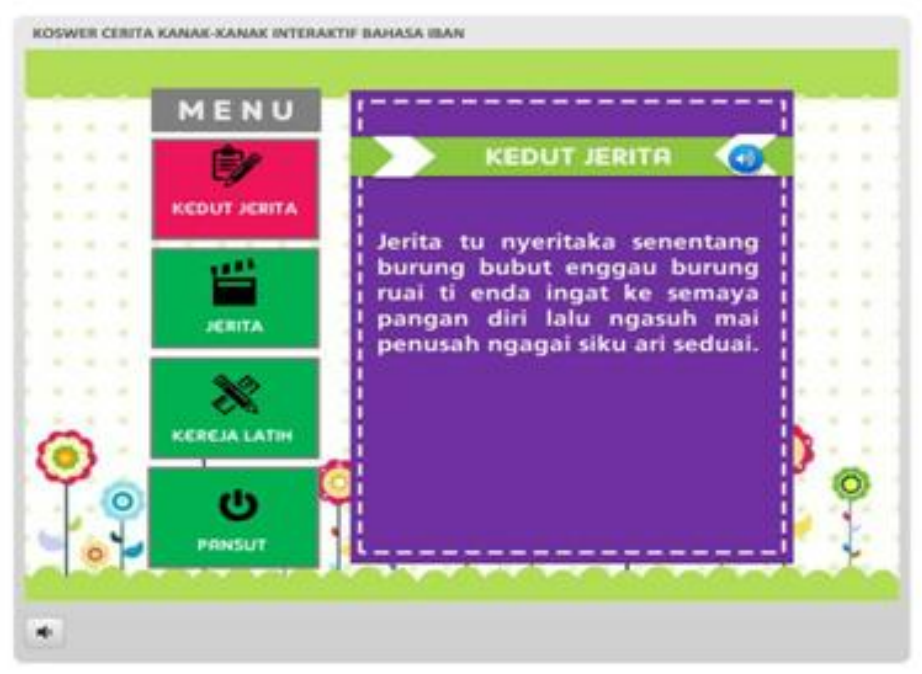

Figure 4: The synopsis page of the IDST

The story page of the ISDT has three icons that will take users to three different links, namely the characters, video story, and vocabulary, as shown in Figure 5. These links introduce users to the main characters of the story that helps users identify the role of each character. In fact, each character's role is explained using relevant images and audio. Once, users have familiarised the role of each character, only then they will be taken to the story scene. The vocabulary space is provided to enable users to learn new words and to further enrich their vocabulary. 


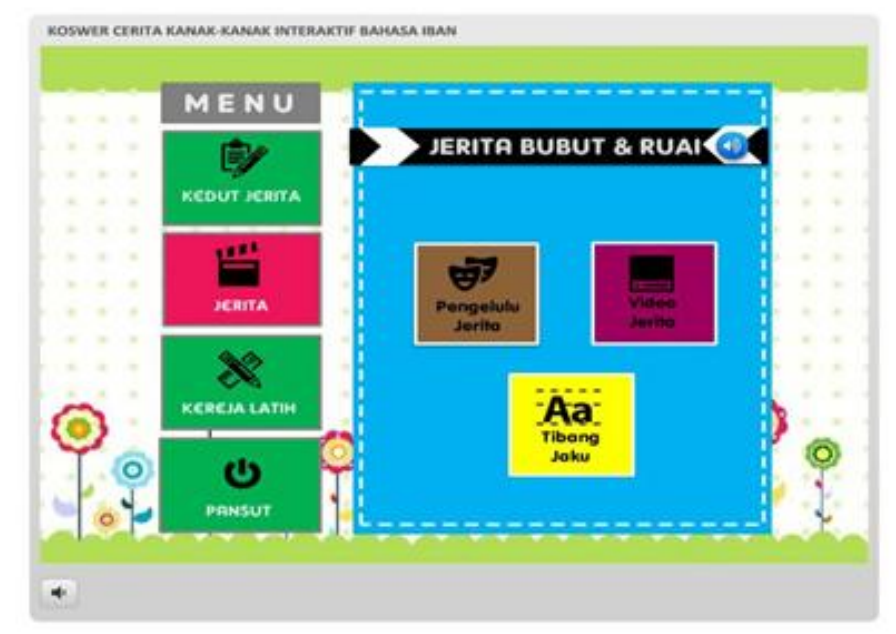

Figure 5: The story page of the IDST

The reinforcement page of IDST has link to a questions bank that helps measure users' understanding of the story learned. Clicking this link will direct users to the interface of the questions bank.

This questions bank has 10 questions, with increasing levels of difficulty, to test users' knowledge in identifying, assessing, and arranging of words. Users are given two attempts to answer each question. Accordingly, each correct and wrong answer will be given award and penalty, respectively, based on specific sound. Nonetheless, for incorrect attempts, the correct answers will be displayed on a "pop-up" box to users for their reference. Users are required to complete the questions in a prescribed time to help assess their achievements, which will be use to measure the user performance at the end of the session. A screenshot of the results interface of the IDST will be displayed.

\section{VIDEO DEVELOPMENT}

The story board that was prepared earlier was used as a guide for the development of the video. Based on the analysis, children's interest and attributes were taken into account in the development by focussing on relevant characters, voice, and landscape.

\subsection{Technique}

In this study, the "clay-mation" technique was used to develop the story video. Essentially, this technique entails forming a character using clay and capturing its movement in sequence. Later, all the movements are combined into a complete video. In fact, this technique is widely used in the entertainment industry to produce many successful children's videos, including the Chicken Run. Before shooting the video, the scenery of the story needs to be developed first to help create a realistic setting. For this video, the selected scene was a jungle, in which the trees were created using plastics. To add greater appeal to the story, the colours for the background and background floor were chosen to be blue and green, respectively. Once the background and background floor were set up, appropriate props, such as trees and clouds, were embedded into the scenery to create a realistic jungle. Subsequently, the development of the four main characters were developed.

After the development of the characters, the shooting session was performed based on the storyboard. The characters were incrementally positioned at various orientations to produce the required movements from scene to scene. Once shooting was complete, the voice recording 
session was carried out to add the sound elements into the story. After the completion of these two sessions, the editing session was performed using Power Director. Using this editing tool, images were combined into a video for a particular scene. Once all the required scenes were edited, they were then combined into a video together with the background music. In addition, subtitles were also added to help viewers understand the conversations or to help teachers read the dialogues of the story with theirs students. Finally, the publishing process was carried out after there were no more amendments to be made to the story. Figure 5 shows one of the video page.

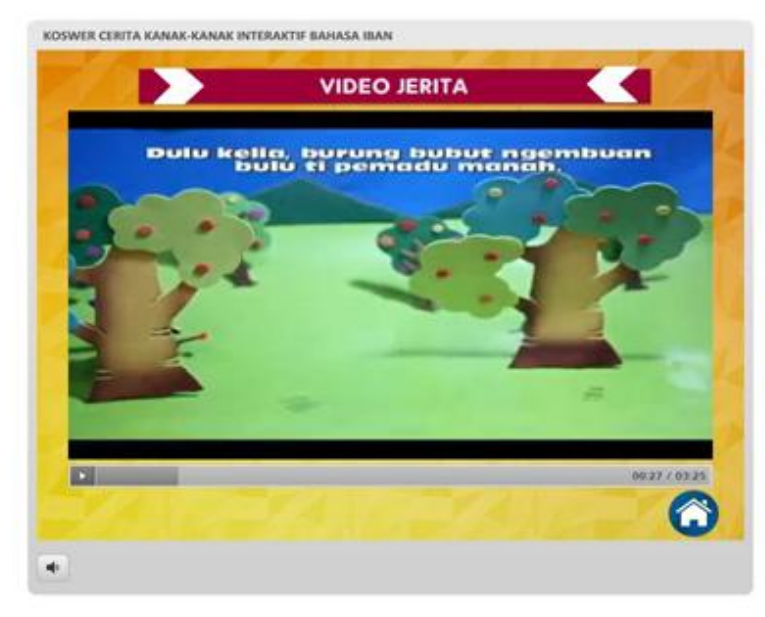

Figure 6: Video page.

\section{DATa AnAlysis, Results AND Discussion}

The data analysis was performed to help the researchers to address the following research question of the study: Do the ease of use and usefulness of the IDST application well received by the interviewees?

To help measure the ease of use of the IDST application, the interviewees were asked to respond to questions that focused on the following elements:

a. The objective of using the IDST application- whether it is clear and easily understood

b. The use of the IDST application - does it entail excessive mental effort

c. The use of the IDST application- does it able to fulfil the needs of users

d. The use of the IDST application- does it easy

e. The scripts - does it eloquently crafted to help students remain focused throughout the learning process

f. The audio narration - does it has high quality sound to help students hear the story with ease

g. The images of the IDST application - does it has high resolution to help students see them with ease

h. The selection of learning contents- does it appropriate for a particular topic and should contain relevant instructional components

i. The music of the IDST application - does it be at an appropriate level that is suitable for the learning contents

j. The story narrated in the IDST application - is it appropriate, not too short or too long

k. The use of grammar in the IDST application- is it appropriate with the chosen dialect.

For the measurement of the usefulness of the IDST application, the following are the elements to which the interviewees were required to respond: 
a. Does the use of IDST application increases the teachers' confidence in teaching the subject matter

b. Does the use of IDST application improve teaching productivity by teachers

c. Does the use of IDST application improve the teachers' class management when teaching the subject matter

d. Does the use of IDST application helps students to learn the subject matter

The interviewees of this study consisted of 10 primary school teachers, who have been teaching the Iban language at several schools located in the districts of Julau and Kapit, Sarawak. In terms of gender, they comprised seven male teachers and three female teachers.

The findings showed that three interviewees ( 1 female, 2 males) and four interviewees ( 1 female, 3 males) had postgraduate and undergraduate qualifications, respectively. Two interviewees (1 female, 1 male) and one male interviewees indicated that they had diploma and certificate qualifications, respectively. In terms of experience, the findings showed that two interviewees (1 female, 1 male) had teaching experiences of less than a year and one male interviewee had no such experience. Four interviewees ( 2 females, 2 males) responded that they had teaching experiences in the range between one and two years. None of the interviewees had any teaching experience in the range between two and three years. Three male interviewees reported that they had teaching experience of more than three years.

For the source of motivation, one male respondent indicated that his friends had motivated him to try the application. Overwhelmingly, seven interviewees ( 2 females, 5 males) indicated that their strong desire to learn the novel tool had motivated them to use such an application. Two interviewees ( 1 female, 1 male) indicated that the prizes offered were their main motivation to use such an application. In this interview, the roles of instructors and other factors did not appear to be the motivation for the interviewees to use such an application. In terms of comfort, exactly half of the interviewees ( 2 females, 3 males) indicated that they were comfortable in using computer technology. Almost equally, four interviewees ( 1 female, 3 males) indicated that they were very comfortable in using such a technology. Surprisingly, one male interviewee indicated that he was not sure about his level of comfort in using computer technology.

All the teachers were also interviewed to elicit their opinions on the ease of use and usefulness of the IDST entitled Jerita Bubut enggau Ruai. For the interview, their opinions on the ease of use and usefulness of the IDST were probed through five and 11 questions, respectively.

\subsection{Usefulness}

For the usefulness of the IDST, the teachers were asked whether the use of such teaching application had improved their confidence in teaching Iban Language. Overwhelmingly, nine teachers indicated their confidence in teaching the subject matter had somewhat improved. In contrast, only one teacher remained neutral, as he was an Iban teacher and had been teaching the subject for over five years, suggesting that such a novel learning tool has a minimal impact on his confidence. Promisingly, all the teachers interviewed agreed that the use of IDST had made them become more productive, with eight of them indicated that the time spent on preparing the topic to be taught was substantially reduced. As such, the time saved can be used to focus on the teaching and learning of other subjects.

All the teachers agreed that the use of IDST helped them become more effective in teaching management, as the novel learning tool has four learning modules, including story, reinforcement, vocabulary, and questions. Such questions, which have been structured based on varying degrees of difficulty, helped the teachers to assess their students' understanding. From students' perspective, eight teachers found the learning application to be extremely useful for their students. In fact, their students were observed to be highly excited and engaged in using IDST as they were 
able to freely select any of the learning modules. By contrast, only two teachers cautioned that only teachers should use this application as they could control the steps and pace of teaching. Furthermore, they were also concerned that students could easily be distracted from learning by the interactive buttons and audio of the application.

Nonetheless, all the teachers agreed that the use of IDST would be able to improve their students' understanding of the topic being learned. Such teachers' positive perception is hardly surprising as multimedia elements of the application would be able to help improve students' cognition, and through repeated practice students would become more knowledgeable. Such perceived usefulness of the learning application seems to concur with Dakich's [17] assertion, as cited in [17], Dakich and Sharda [18], who states that digital storytelling applications serve as a helpful educational tool that provides a vehicle for combining digital media with innovative teaching and learning practices. Moreover, digital storytelling is a powerful tool to integrate instructional messages with learning activities to create more engaging and exciting learning environments. It is a meaningful approach for creating a constructivist learning environment based on novel principles of teaching and learning [19].

Arguably, the use of various multimedia elements of such applications can help improve student learning, as Muhamad Hasan [20] asserts that, based on the pyramid of knowledge acquisition, $83 \%$ of learning is through visual perception, compared to tactile, olfactory, and aural perceptions. As such, the use of appropriate visual elements of such applications helps facilitate the process of knowledgeable acquisition Colours play an important role in the cognitive development of children's, as they can readily attract students' attention to learning contents, by which they can engage in activities that nurture their creative thinking [20]. Nonetheless, colours should be used judiciously in terms of types and numbers so as not to overwhelm or distract students.

Moreover, Smeda, Dakich and Sharda [18] state that digital storytelling is an innovative approach to teaching and learning that provides opportunities for integrating student-centred and interactive teaching and learning in technology- rich environments, naturally amalgamating human creativity and technology. As such, new multimedia DST applications seems to be more efficacious than the conventional textbook when used with proper planning in the right context [21]. More importantly, Allor and Mccathren [22] assert that children's stories can help improve the developments of children's language and communication. They contend that, through storytelling, children will be able to hear the proper dictions, express their ideas and opinions, and relate stories in either oral or written form. Additionally, they will be able to understand the new literary elements and vocabulary, ultimately enabling them to communicate much better.

Furthermore, DePorter, Reardon, and Nourie [23]contend that learning using cartoons can help create a learning environment that imbues a sense of happiness among learners. [24] asserts that cartoons can be used more effectively in teaching if they provide information that relate to the teaching material. Their contention is consistent with Dryden and Vos [25] arguments that using cartoon in learning can make students become excited, happy, and enthusiastic, thus making learning not only effective but also fun. Naturally, being in a state of happiness, children will learn without too much pressure and, as such, gain better retention of what has been taught. According to Dalacosta et. al. [26], the presentation of cartoons in a multimedia application gave it an obvious advantage as a learning aid, based upon the presentation of specific scientific knowledge in a popular form that is enjoyed by most young students. In teacher's hands, animated cartoons are consider to be an effective supplementary didactical tool that can used for reaching students learning goals inside the classroom. This is supported by Khalida, Meeraha and Halim [27], teachers view that teaching and learning using cartoons can create positive learning environment for the students and able to stimulate students' imagination and creativity. 
Hence, teachers should try to explore and use cartoonish characters to help them create emotive learning environments to better engage their students. In this regard, learning applications should be developed using good design principles to ensure their applications in learning can motivate and provide more space for students to learn and result in better learning performance [28]. For further improvements, such learning applications can be supplemented with supporting materials and clear examples and implemented using well-crafted lesson plans to elicit better feedback from students during the learning process [29].

\subsection{Ease of Use}

Ease of use is measure of work productivity, performance, and effectiveness. In this study, ease of use is defined as the confidence of user in using the application without too many efforts. The findings showed all the teachers strongly agreed that the intended objectives of the application was clear and easily understood. They totally agreed that the selection of the learning contents was appropriate for the topic to be learned based on relevant teaching components and grammar used by each character of the story in the learning application. Moreover, the findings showed nine teachers agreed that the application was easy to use as expected. By contrast, only one teacher indicated that he had some difficulties in using the application, given his poor skills in computer.

For the quality of contents, eight teachers agreed that the scripts had been carefully written that helped students to comprehend the whole story with ease. Interestingly, two teachers believed that the scripts needed further improvement to make the story more interesting and appealing such that their students could virtually immerse themselves into the roles of the story's characters.

Eight teachers interviewed agreed that the images used in the application were clear and appropriate with the story's characters. The other two teachers, however, opined that the images needed further improvement to attract students' attention. For the musical aspect, eight teachers considered that the music of the digital story was not only relevant but also highly interesting. On the other hand, the remaining two teachers were not satisfied with the musical background used in the application, emphasizing that it was not interesting.

Although the audio quality was deemed satisfactory, a majority of the teachers interviewed indicated that more efforts were entailed to improve the IDST application in this particular aspect. They strongly stressed that the narration of the application could be made clearer and conversational to ensure students would be able to concentrate during the teaching and learning process. Their opinions seems to concur with Scott County Schools' (Kentucky) Digital Storytelling Rubric [30] that emphasizes consistent presentation by speaking slowly in a conversational style. Finally, six teachers interviewed registered their strong approval with regard to the contents of the story, indicating that the contents were both adequate and relevant to help students gain better understanding of the story. The remaining four teachers, however, highlighted that the presentation of the story was relatively short to inspire students with the messages of the story. As such, they recommended the story to be made much longer by focussing on each character's role such that students would be much more inspired with the story.

\section{Conclusion}

The findings of this study showed that two important elements of user acceptance of the IDST, namely usefulness and ease of use, were highly rated by the teachers interviewed. Given these promising results, such a novel learning application can be used as an alternative teaching tool to further improve the current practice of teaching Iban language to primary school children. Moreover, such a learning tool will be able to help Iban language teachers, especially less experienced teachers, in teaching the subject matter more effectively and efficiently. More revealingly, students were reportedly seemed excited and inspired with the learning of Iban language using the IDST application. Nonetheless, more efforts are entailed to make such a 
The International Journal of Multimedia \& Its Applications (IJMA) Vol.9, No.4/5/6, December 2017

learning tool more potent such as to optimise the teaching and learning of the subject matter. Furthermore, future research should focus on students' achievement when using such a tool in their learning.

\section{ACKNOWLEDGEMENTS}

The authors would like to thank UPSI for granting this research.

\section{REFERENCE}

[1] Chemaline Osup (2011). Morfologi jaku iban malin nembiak enggau pengajar, Emeritus Publications.

[2] Peng, C. F. (2012) Developing Children's Literacy Resources, Educational Research and Reviews, 7(7), 155-168.

[3] Pandit, P. and Tahiliani, S. (2015) AgileUAT: A Framework for User Acceptance Testing based on User Stories and Acceptance Criteria, International Journal of Computer Applications, Vol. 120, No.10, pp 16-21.

[4] Heinich, R., Molenda,M, \& Russel, J.D. (1993) Instructional Media and the new technologies of instruction (4th ed.). New York: Macmillan.

[5] Pitler, H. J. (2006) Viewing technology through three lenses. Principal, 85(5), 38-42.

[6] Papadimitriou, E., Kapaniaris,A., Zisiadis,D. and Kalogirou,E. (2013) Digital Storytelling in Kindergarten: An Alternative Tool in Children's Way of Expression, Mediterranean Journal of Social Sciences, 4(11).

[7] Pieterse,G. and Quilling, R. (2010). The impact of digital story-telling on trait Emotional Intelligence (EI) amongst adolescents in South Africa - a case study, Procedia Social and Behavioral Sciences, $28,156-163$.

[8] Psomos, P and Kordaki, M. (2012) Pedagogical Analysis of Educational Digital Storytelling Environments of the Last Five Years, Procedia Social and Behavioral Sciences, 46, 1213 - 1218.

[9] Bran, R (2010) Message in a bottle Telling stories in a digital world, Procedia Social and Behavioral Sciences, 2, 1790-1793.

[10] Miswan, M., Hamedi,A., \& Saad,N. (2014). Pembangunan Aplikasi IPAD untuk Kanak-kanak. In Proceedings of 1st International Conference on Creative Media, Design \& Technology (REKA2014), pp 1-19.

[11] Tsai,P.S., \& Huang,L. (2014). Usability Analysis of Interactive Childrens' IPAD story book. In Proceedings of HCI International 2014 - Posters' Extended Abstracts, pp 643-648.

[12] Wu, W.H., Jim Wu, Y.C., Chen,Cy., Kao,H.Y., Lin,C.H. \&Huang,S.H. (2012) Review of trens from mobile learning studies: A meta-analysis. Computers \& Education, 59 (2), 817-827.

[13] Kukulska-Hulme, A. and Shield, L. (2008) An overview of mobile assisted language learning: From content delivery to supported collaboration and interaction. ReCALL, 20 (3), 271-289.

[14] Fallahkhair, S., Pemberton, L., \& Griffiths, R. (2007). Development of a cross-platform ubiquitous language learning service via mobile phone and interactive television, Journal of Computer Assisted Learning, 23,321-325.

[15] Xiaobin, C. (2012). The MALL: Where language learning takes place anytime, anywhere, In Proceedings of 2012 International Symposium: Educational Research and Educational Technology, pp 462-466.

[16] Fernández-López, Rodríguez-Fórtiz, Rodríguez-Almendros, \& Martínez-Segura, 2013. Mobile learning technology based on iOS devices to support students with special education needs, Computers \& Education, 61, 77-90. 
The International Journal of Multimedia \& Its Applications (IJMA) Vol.9, No.4/5/6, December 2017

[17] Dakich, E. (2008) Towards the social practice of digital pedagogies in N. Yelland, G. Neal \& E. Dakich (eds.), Rethinking education with ict: new directions for effective practices, pp. 13-30. Sense Publishers.

[18] Smeda, N and Dakich, E and Sharda, N. (2010). Developing a framework for advancing e-learning through digital storytelling, in Proceedings of IADIS International Conference e-learning 2010, pp $169-176$

[19] Smeda, N and Dakich, E and Sharda, N. (2014). The effectiveness of digital storytelling in the classrooms: a comprehensive study. Smart Learning Environments, 1 (1).

[20] Muhamad Hasan Abdul Rahman (2000). Media pengajaran: penghasilan bahan pengajaran berkesan, Penerbit Universiti Putra Malaysia.

[21] Harun, J., Aris, B. \& Tasir, Z. (2003). Multimedia dalam pendidikan, PTS Publications.

[22] Allor, J. H. \& McCathreen, R. B. (2003). Developing Emergent Literacy Skills Through Storybook Reading, Intervention In School And Clinic, 39(2).

[23] DePorter, B., Reardon, M. \& Nourie, S. S. (2000). Quantum Teaching: Orchestrating Student Success, Allyn and Bacon.

[24] Dalacosta, K., Paparrigopoulou-Kamariotaki, M., Pavlatou, E. A. (2011). Can we assess pupil's science knowledge with animated cartoons?, Procedia Social and Behavioral Sciences, 15, pp 32723276.

[25] Dryden, G. \& Vos, J. (2001). The learning revolution: to change the way the world learn, Network Educational Press.

[26] Dalacosta, K., Kamariotaki-Paparrigopoulou, M., Palyvos, J.A. and Spyrellis, N. (2009) Multimedia application with animated cartoons for teaching science in elementary education, Computers \& Education, Vol. 52, pp 741-748.

[27] Khalida, H., Meeraha, T. S. and Halim, L., (2010) Perception towards usage of cartoon in teaching and learning physics. Procedia Social and Behavioral Sciences, 15, pp 3272-3276.

[28] Milutinović Miloš, Barać Dušan, Despotović-Zrakić Marijana, Marković Aleksandar (2011) Developing mobile application for learning japanese language fonjapgo. Management-Časopis $\mathrm{Za}$ Teoriju I Praksu Menadžmenta, 16(60), 27-33.

[29] Kamarudin Hj. Husin \& Siti Hajar Hj. Abdul Aziz (2003) Pedagogi untuk Asas Pendidikan, Kumpulan Budiman.

[30] Digital Storytelling Rubric from Scott County Schools,access from http://electronicportfolios.com/digistory/DS-rubric.pdf on 14th September 2017.

\section{Authors}

Dr Aslina Saad is working as a Senior Lecturer in Faculty of Art, Computing and Creative Industry. She is a graduate in Bachelor of Information Technology (Science and System Management) and Master of Science (Information Technology). She received her $\mathrm{PhD}$ in Computer Science (Information Systems) from University of Loughborough and is currently attached to Universiti Pendidikan Sultan Idris. Her research interests are on Computer in Education, Management Information System, Artificial Intelligence and Knowledge Management. Currently, she is teaching System Analysis and Design, Software Design, Software Project and Information

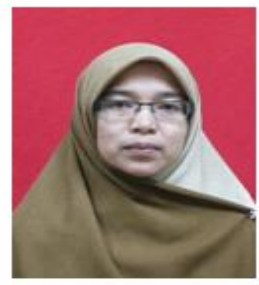
System Development courses.

Saira Banu Omar Khan is working as a Lecturer in Faculty of Art, Computing and Creative Industry. She is a graduate in Bachelor of Computer Science (Hons.) and obtained her Master of Science (Computer Science) degree from Universiti Sains Malaysia. Her research interests are on Multimedia in Education, Educational Technology, Educational Software, Multimedia Courseware and Learning Disability. Her teaching interests include Multimedia in Education, Information \& Communication Technology and Programming.

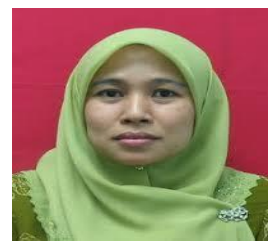


The International Journal of Multimedia \& Its Applications (IJMA) Vol.9, No.4/5/6, December 2017

Dr. Nor Hasbiah Ubaidullah is working as an Assoc. Prof. of IT in Faculty of Art, Computing and Creative Industry. She has 25 years of teaching experience in several universities. She is a graduate in Bachelor of Computer Science (Hons.) and obtained her Master of Science (Information Systems) degree from University of Salford. She received her PhD in Information Technology from Universiti Kebangsaan Malaysia and is currently attached to Universiti Pendidikan Sultan Idris. Her research interests are on Educational Technology, Educational Software, Courseware/Software Engineering and Learning Disability. Her teaching interests include Software Engineering, Information \& Communication Technology and Programming.

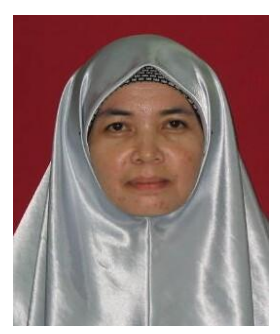

